\title{
Piggybacked by PEGylation?
}

\author{
Kichul Shin
}

Division of Rheumatology, Seoul Metropolitan Government-Seoul National University Boramae Medical Center, Seoul, Korea
Received: October 11, 2018 Accepted: October 18, 2018

\section{Correspondence to \\ Kichul Shin, M.D.}

Division of Rheumatology, Seoul Metropolitan Government-Seoul National University Boramae Medical Center, 20 Boramae-ro 5-gil, Dongjak-gu, Seoul 07061, Korea

Tel: +82-2-870-3204

Fax: +82-2-870-3866

E-mail: kidebı@snu.ac.kr

\section{See Article on Page 1224-1233}

Physicians currently treat rheumatoid arthritis (RA) (and other systemic rheumatic diseases) more effectively than a decade ago with the help of an armamentarium of disease-modifying antirheumatic drugs (DMARDs). Biologic DMARDs (bDMARDs), in particular, have given patients with severe disease activity a much better quality of life and joint mobility. bDMARDs or biologics, are monoclonal antibodies or immunoglobulin $\mathrm{G}$ (IgG) fusion proteins produced in cells that target a specific molecule or cell surface marker. The treatment strategy for RA was revolutionized after the introduction of bDMARDs [1]; tumor necrosis factor $\alpha$ (TNF- $\alpha$ ) inhibitors (TNFis) were first included, with different subsets of biologics added later on. Table 1 lists the bDMARDs that are currently approved for use in Korea. Among these, TNFis have the greatest number of agents.

Certolizumab pegol (CZP) differs from other TNFis due to its PEGylated form. It consists of a PEGylated Fab' fragment of a humanized anti-TNF- $\alpha$ antibody [2]. The PEGylation process includes both covalent and non-covalent attachment or amalgamation of polyethylene glycol (PEG) polymer chains to molecules and macrostructures such as a drug, therapeutic protein, or vesicle. The covalent attachment of PEG to a drug or therapeutic protein can mask the agent from the host's immune system, reducing immunogenicity and prolonging its circulatory time by reducing renal clearance. Other PEGylated pharmaceuticals include peginteferon- $\alpha$, pegloticase, pegfilgastrim, etc.

A recent systematic review of the Cochrane database reported that CZP (200 mg every other week, compared to the comparator) demonstrated an American College of Rheumatology 50\% (ACR50) improvement criteria (in terms of pain, function, and other symptoms of RA) score of $25 \%$ (95\% confidence interval [CI], $20 \%$ to $33 \%$ ) and the number of treatments required to provide an additional beneficial outcome was 4 (95\% CI, 3 to 5 ) at 24 weeks [3]. The proportion of patients achieving remission (Disease Activity Score < 2.6 ) was $10 \%$ (95\% CI, $8 \%$ to ${ }_{16 \%}$ ) in the meta-analysis. Other studies have demonstrated its efficacy in patients with ankylosing spondylitis, psoriatic arthritis, and inflammatory bowel disease.

The article by Kang et al. [4] in this issue reports a randomized, double-blinded, placebo-controlled study of add-on therapy of CZP to methotrexate (MTX); this is the first Korean CZP trial for RA patients with active disease. The primary outcome of that study (ACR2O) corroborated the findings in the literature, and the improvement of patient-reported outcomes was also 
Table 1. Subsets of biologic DMARDs approved for RA treatment in Korea

\begin{tabular}{|c|c|c|}
\hline Subset & Agent & Dosage and interval \\
\hline \multirow[t]{7}{*}{ TNF- $\alpha$ inhibitor } & Infliximab $^{\mathrm{a}}$ & $3 \mathrm{mg} / \mathrm{kg}$ IV o, 2, 6 weeks, followed by every 8 weeks \\
\hline & Etanercept $^{\mathrm{a}}$ & $50 \mathrm{mg}$ SQ every week or \\
\hline & & 25 mg SQ every other week \\
\hline & Adalimumab $^{\mathrm{a}}$ & $40 \mathrm{mg}$ SQ every other week \\
\hline & Golimumab & 50 mg SQ every week \\
\hline & & $2 \mathrm{mg} / \mathrm{kg}$ IV o, 4 weeks, followed by every 8 weeks \\
\hline & Certolizumab pegol & $\begin{array}{l}400 \mathrm{mg} \text { SQ 0, 2, } 4 \text { weeks, followed by } 200 \mathrm{mg} \text { every other } \\
\text { week }\end{array}$ \\
\hline \multirow[t]{5}{*}{ CTLA-4 IgGı fusion protein } & Abatacept & $<60 \mathrm{~kg}: 500 \mathrm{mg}$ \\
\hline & & 6o-100 kg: $750 \mathrm{mg}$ \\
\hline & & $>100 \mathrm{~kg}: 1,000 \mathrm{mg}$ \\
\hline & & IV o, 2, 4 weeks, followed by every 4 weeks or \\
\hline & & 125 mg SQ every week \\
\hline Anti-CD2o antibody & Rituximab $^{\mathrm{a}}$ & 1,000 mg IV o, 2 weeks, followed by every 6 months \\
\hline Anti-IL-6 receptor antibody & Tocilizumab & $\begin{array}{l}4-8 \mathrm{mg} / \mathrm{kg} \text { IV every } 4 \text { weeks or } \\
162 \mathrm{mg} \text { SQ every other week }\end{array}$ \\
\hline
\end{tabular}

DMARD, disease-modifying antirheumatic drug; RA, rheumatoid arthritis; TNF- $\alpha$, tumor necrosis factor $\alpha$; IV, intravenous; SQ, subcutaneous; CTLA, cytotoxic T-lymphocyte-associated protein; IgG1, immunoglobulin G1; CD, cluster of differentiation; IL-6, interleukin 6.

${ }^{a}$ Agents that currently have a licensed biosimilar(s).

significant compared to the control group. Interestingly, the post hoc analysis of a subset of early responders $(43.8 \%$ of CZP users) at 4 weeks after two injections of $400 \mathrm{mg}$ revealed that a greater proportion of patients achieved remission or low disease activity at 24 weeks. In contrast, a study by Keystone et al. [5] predicted the 52-week response of CZP after three injections. Due to the different dosing schedules, concomitant medications, and other confounding factors, prediction of the time point of the long-term treatment response to different bDMARDs is expected to vary [6]. Studies have also found that CZP provided rapid and sustained clinical improvement in RA patients regardless of prior TNFi use [7]. Whether CZP or other bDMARDs is a better alternative in this population needs further investigation.

The safety profile of the CZP plus MTX group in the study by Kang et al. [4] was largely comparable to those used in previous studies. The meta-analysis described above revealed that serious adverse events were statistically, but not clinically significantly, more frequent for CZP with an absolute rate difference of 3\% (95\% CI, $1 \%$ to $4 \%$ ) [3]. Evidently, PEGylation does not alter the incidence of safety signals of 'unmodified' TNFi. Whether PEGylation could augment drug survival is yet to be de- termined; a recent real-world study in RA did not lead to that conclusion [8].

The era of few effective treatments for active RA has passed: there is now a long list of drugs that can help patients. The treatment paradigm has also shifted to shared decision-making in terms of which bDMARD to initiate, and physicians should discuss the administration route, loading schedule, dosing interval, and possible adverse events of candidate agents with their patients. For example, TNFi are administered via intravenous or subcutaneous routes and this decision may be affected by multiple factors such as drug accessibility, age, costs, clinical setting, and others. In terms of dosing intervals, infrequent dosing has merits, although this means the drug would have a longer halflife and could therefore be detrimental in post-treatment situations with a severe adverse drug reaction or infection.

New methods of engineering (i.e., hybridoma generation using human IgG transgenic mice) or modification (i.e., PEGylation) have been employed to generate biologics with less antigenicity or fewer drug reactions, and improved drug survival. Whether these agents are superior to others in terms of efficacy or safety will re- 
main uncertain unless a head-to-head clinical trial is conducted; such a trial is unlikely to be conducted in the near future. What is more important is that clinicians are now equipped with effective arsenals for the treatment of RA, and the focus in the future should be improving treatment strategies and optimizing drug selection to help more patients achieve early disease remission [9].

\section{Conflict of interest}

No potential conflict of interest relevant to this article was reported.

\section{REFERENCES}

1. Smolen JS, Landewe R, Bijlsma J, et al. EULAR recommendations for the management of rheumatoid arthritis with synthetic and biological disease-modifying antirheumatic drugs: 2016 update. Ann Rheum Dis 2017;76:960-977.

2. Kaushik VV, Moots RJ. CDP-870 (certolizumab) in rheumatoid arthritis. Expert Opin Biol Ther 2005;5:601-606.

3. Ruiz Garcia V, Burls A, Cabello JB, Vela Casasempere P, Bort-Marti S, Bernal JA. Certolizumab pegol (CDP870) for rheumatoid arthritis in adults. Cochrane Database Syst Rev 2017;9:CDoo7649.
4. Kang YM, Park YE, Park W, et al. Rapid onset of efficacy predicts response to therapy with certolizumab plus methotrexate in patients with active rheumatoid arthritis. Korean J Intern Med 2018;33:1224-1233.

5. Keystone E, Heijde Dv, Mason D Jr, et al. Certolizumab pegol plus methotrexate is significantly more effective than placebo plus methotrexate in active rheumatoid arthritis: findings of a fifty-two-week, phase III, multicenter, randomized, double-blind, placebo-controlled, parallel-group study. Arthritis Rheum 2008;58:3319-3329.

6. Kumar N, Naz S, Quinn M, Ryan J, Kumke T, Sheeran T. Treatment of rheumatoid arthritis with certolizumab pegol: results from PROACTIVE, a non-interventional study in the UK and Ireland. Adv Ther 2018;35:1426-1437.

7. Weinblatt ME, Fleischmann R, van Vollenhoven RF, et al. Twenty-eight-week results from the REALISTIC phase IIIb randomized trial: efficacy, safety and predictability of response to certolizumab pegol in a diverse rheumatoid arthritis population. Arthritis Res Ther 2015;17:325.

8. Ebina K, Hashimoto M, Yamamoto W, et al. Drug retention and discontinuation reasons between seven biologics in patients with rheumatoid arthritis: the ANSWER cohort study. PLoS One 2018;13:e0194130.

9. Bluett J, Barton A. Precision medicine in rheumatoid arthritis. Rheum Dis Clin North Am 2017;43:377-387. 